\title{
An environmental economic assessment of water sharing alternatives for the Broken catchment in the Northern Victoria
}

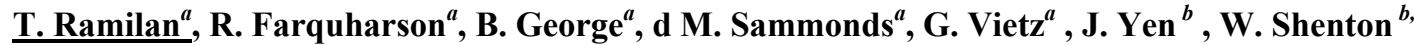 \\ K. Dassanyake ${ }^{a}$, B. Cullen ${ }^{a}$, M. Stewardson ${ }^{a}$, and A. Western ${ }^{a}$ \\ ${ }^{a}$ The University of Melbourne, Victoria \\ ${ }^{b}$ Monash University, Victoria \\ Email: ramilant@unimelb.edu.au
}

\begin{abstract}
Combinations of climatic factors and potential policy initiatives such as Sustainable Diversion Limits (SDLs), which define water diversions for consumption while maintaining environmental assets and ecosystem functions, will continue to challenge water resource management in the future. Irrigation currently consumes major share of water entitlements and is likely to be affected in terms of reduced yield and quality as a result of reduced water availability. Previous studies have quantified the economic impacts of water sharing and climate change by only changing irrigable area as a response to variations in water availability. In this study we incorporate complex crop water profit functions, irrigation technology, alternative cropping systems and detailed environmental responses to capture economic and environmental tradeoffs under different climate scenarios and SDLs. Economic and environmental tradeoffs are valued in terms of opportunity cost of foregone agricultural profit and benefit transfer from existing environmental valuation studies. This paper presents environmental and economic responses in the Broken River catchment to analyse alternative water sharing arrangements and examine the tradeoffs.
\end{abstract}

The modelling framework includes a diverse range of tools. Irrigator demand was modeled through representative farm models for irrigated dairy, horticulture and cropping and fodder industries providing optimal water use at the farm level. These were scaled up to the catchment level according to land use areas. The technical coefficients for representative farm models were obtained from experimental trials and biophysical modeling tools, such as DairyMod and APSIM, which provide a way of assessing the impact of a range of changes on pasture systems. The objective function in the model was the maximization of the total gross margin for the farm and subject to constraints. Gross margin was defined as the difference between returns from agricultural produce plus stock sales and variable costs.

The environmental assets of concern were native fish, macro invertebrates, riverine vegetation and geomorphology. An expert panel of scientists was formed to consider these categories of environmental requirements (assets) and developed a set of priorities to achieve asset improvement and maintenance of ecosystem functions. Augmented flow requirements for the maintenance of environmental assets were quantified by eflow predicter developed by the eWater Cooperative Research Centre (CRC),against the base line historical regulated river flow.

The allocation of water to meet environmental demands was simulated using a daily water resources allocation simulation model Source River developed by eWater CRC, which includes representations of different demands, stream flow and the effect of water supply system constraints. Implications of varying simulated allocations to environmental and irrigation demand were quantified. With decreasing allocation, relative to demand, the economic benefit (for agricultural demand) and the environmental benefits (for the environmental demand) were compromised.

Results from the analysis depended on the types of analysis and units of measurement. Environmental outcomes for native fish populations and riverine vegetation were presented in meeting the objectives of environmental improvement specified in the Water Act 2007. Farm-level results were presented as changes in total farm gross margin. Catchment water supply outcomes were presented as changes in stream flows associated with different water sharing rules. These outcomes can be useful for valuing environmental flows by applying benefit transfer of environmental values.

Keywords: Economic, environment, agriculture, Murray-Darling Basin, Broken River catchment 


\section{INTRODUCTION}

The Broken River is one of the tributaries of the Goulburn River in north-eastern Victoria. The catchment's storage Lake Nillahootie was built in 1967 to harness the flows of the Broken River to meet irrigation, domestic and stock, and urban water supply requirements. Only $16 \%$ of reservoir flow is intercepted for consumptive purposes, because of its limited capacity of 41 GL (GMWater, 2011). Major consumptive use is irrigation. The central area of the catchment is used for grazing and mixed cereals with a large area of intensive irrigation and cropping. Combinations of climatic factors and new policy initiatives such as diversion of water from irrigation schemes to rivers and streams (environmental flows) are likely to cause water scarcity, with potential affect on the irrigation industry. Although the major waterways have good riparian vegetation, in stream snags and fish cover in permanent pools, they can suffer from low flows during the non-irrigation period and a lack of flooding during spring (as a result of flow regulation) which inhibits spawning of native fish. Lake Nillahcootie stores most of the run-off from the higher rainfall area resulting in low winter flows in parts of the Broken River and Broken Creek. Many floodplain wetlands now experience reduced inundation frequency and duration due to changes in river flow and timing (Kingsford, $2000\{$ Walker, 1993 \#514; Walker \& Thoms, 1993 \{Kingsford, 2000 \#513)\}. In order to successfully restore environmental functions, the appropriate wetting regime needs to be re established.

Estimation of environmental flow requirement should take into account the temporal and spatial differences in water requirements as well as implications on competing uses. This is not a simple exercise, but requires indepth site-specific ecological, hydrological and farm systems knowledge. It is increasingly difficult to quantify ecosystem service values of improved river health from environmental flows not extracted for irrigation or other consumptive uses. Robust estimates of these values require an understanding of ecological responses to increased flows.

To quantify the agricultural and environmental implications of altering flow regime we use a diverse range of modeling tools. Irrigator demand was modeled through representative farm models for irrigated dairy, horticulture and cropping and fodder industries providing optimal water use at the farm level and scaled up to the catchment level according to land use areas. Environmental flow requirements were identified through expert panel and quantified through a range of tools, and modeled and valued. So far most studies considered only agricultural options at the extensive margin, our model extends the traditional approach by endogenising changes at the intensive margin, such as changed feeding practices, water production functions, technologies (e. g. deficit irrigation ) and crop varietal mix.

This expands our ability to evaluate the impacts of alternative water management strategies in response to increasingly scarce water supplies. It allows assessment of social welfare benefits and costs of alternative public water resource policies.

\section{MODELLING FRAMEWORK AND EMPIRICAL MODELLING}

This study combines appropriate farm economic, hydrologic water allocation and ecological models as components of an integrated modelling framework (Figure 1). The following sub sections discuss individual components of modeling and data and the detailed assumptions used in empirical modeling .

\subsection{Farm Modelling}

Farm economic models were built for irrigated dairy, perennial horticulture and irrigated cropping. These models included crop diversity in orchards and complicated management on dairy farms, previous modelling exercises only used broad catergorisation. These models include different water use technologies, alternative cropping, various pasture pool constraints, crops and conserved feed, feed transfers and reconcilations, livestock numbers, limits to crop and pasture areas and volumetric allocation of water.

Total farm gross margin (TGM) was defined as the difference between returns from agricultural produce plus produce sales and variable costs. The objective function in the model is the maximization of the total gross margin for the farm and subject to constraints on water availability and other resources. The farm models were built using GAMS modeling language and solved using a linear programming algorithm. The outputs of this optimisation process were the optimal livestock and cropping system, the corresponding TGMs, demand for irrigation water use. The solution obtained by optimising is dependent on two important climate related 
variables firstly the seasonal water demand, i.e. variation of net crop water requirements with seasonal rainfalls, and secondly the supply to allocation for the season in concern. Simulations are carried out for average, wet and dry seasons.

Information for farm economic models has been generated by simulation models and results from experimental trials. Dry matter production and water use requirements of annual pasture, lucerne, irrigated wheat and maize crops were derived from long term simulations from The Agricultural Production Simulation (APSIM) model (Keating, Carberry, Hammer, Probert, \& Robertson, 2003). Perennial Pasture requirements were derived from DairyMode (Johnson et al., 2008). Although the water entitlements (or pumping licenses) are fixed for farms, on-farm water delivery can be varied between model runs using the percentage allocation.

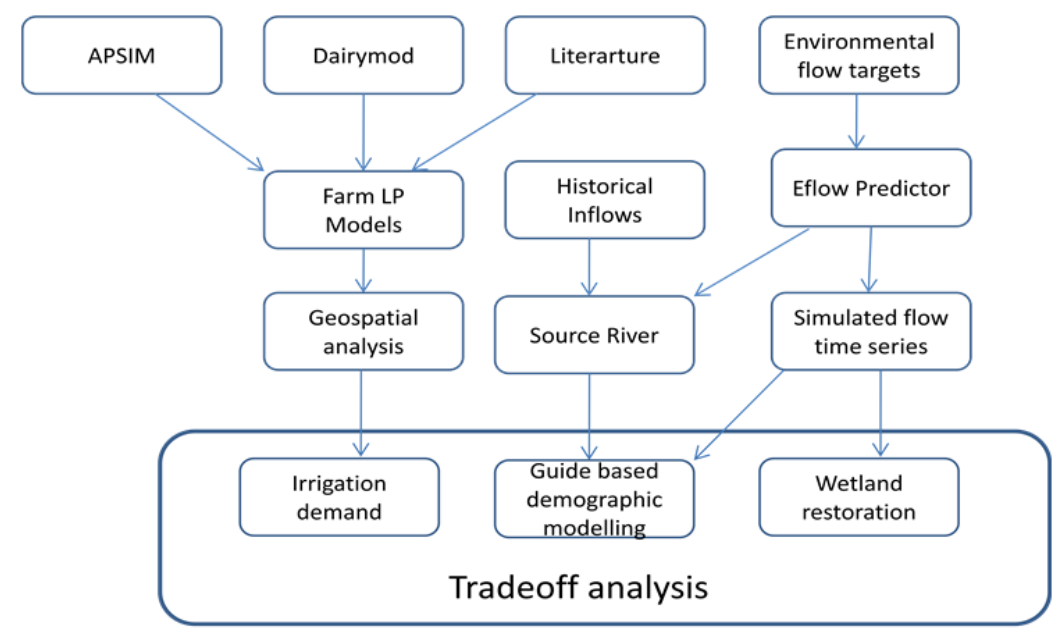

Figure 1 Modelling framework of different modeling components

\subsubsection{Up scaling of farm models}

The total catchment irrigation demand for different farm types was produced by scaling up according to land use areas estimated using geo spatial analysis. The major input data for up scaling was detail of the agricultural enterprises and crop areas in the catchment. Unfortunately, reliable and up-to-date data on irrigated crop areas at the desirable degree of resolution and in the required format were not readily available, and it was necessary to apply some degree of processing to the available land use data obtained from Department of Primary Industries, Victoria (DPI, 2009). These data were calibrated using area estimates of agricultural census data 2006 at statistical local area level. Since this data refers to the period before another water storage in the catchment (Lake Mokoan) was decommissioned, individual water entitlements held by irrigators in the Broken River catchment were obtained from Victorian Water Register and aggregated to derive total entitlement volume. The final crop area numbers included a calibration adjustment factor to reflect total entitlement volume. Based on spatial analysis, the irrigation dependent industries in the Broken River catchment were perennial horticulture, dairying and annual crops and fodder. Annual crop is represented by irrigated wheat.

\subsection{Water flow simulations}

Water flow was simulated by the Source Rivers model, which is designed to support planning and operational aspects of river system management (eWater, 2011). It simulates the physical and management aspects of river systems at a range of spatial and temporal scales. A Source Rivers model was set up for the Broken River catchment. To assess the water resources available, a detailed hydrologic modelling and stream flow simulation was carried out using the hydrologic modelling tool SimHYD. SIMHYD is one of the 
rainfall-runoff models in RRL (Rainfall-Runoff Library), a software product in the Catchment Modelling Toolkit (www.toolkit.net.au/rrl).

The calibrated and validated hydrological model was used to simulate historical flows since 1896 and was used as input in the Source Rivers model.

This paper uses deterministic equivalent of monthly average flow simulations for the period from 1984 to 2005. Deterministic equivalent refers to the probable occurrence of a specific amount of water in a probability distribution. The deterministic equivalents were used to derive empirical cumulative probability distribution for each month. Figure 2 is a graphic representation of the empirical cumulative probability distribution for the month of February. From these distributions, the dry season rainfall is based on the $25^{\text {th }}$ percentile of the data, the wet season is $75^{\text {th }}$ percentile and the $50^{\text {th }}$ percentile is the moderate season.

Given the limited capacity of the system to control the natural flows in the Broken River Catchment only $20 \%$ of flow is assumed to be used for irrigation, environmental water and system maintenece. These uses are defined by Yong (2010). Environmental water refers only to the water that is available for diversion onto land on either side of the river stem and other similar purposes. Water needed to maintain flow in the stem of the river, allow navigation, cover evaporative losses etc called maintenance water. The remaining water is treated as flood water, which refers to the water that has to be allowed to flow through the system because this water can't be kept within the stem of the river system. Sustainable diversion limit (SDL)is the maximum volume that can be diverted from a catchment while protecting the environmental values of the catchment's waterways.

Main mode of irrigation water abstraction in the catchment is private diversion . The irrigation season for private diverters (ie customers who divert water directly from a river) is usually between 1 July and 30 June. The volume of water available for allocation at any time is the volume actually held in storages, minus upfront commitments, the losses incurred by the storage and delivery of water (eg seepage and evaporation). The up-front commitments include urban water supplies, environmental flows, and carryover when it is permitted.

The minimum flow requirement for pump access was assumed to be $50 \mathrm{ML} /$ day for allocations at $100 \%$ or above. Due to the lack of information as to how the minimum pump access would vary between $0 \%$ and $100 \%$ it was assumed that a linear relationship would apply. This would represent potential changes to operation of the system such as shortening of the irrigation season in low allocation years.

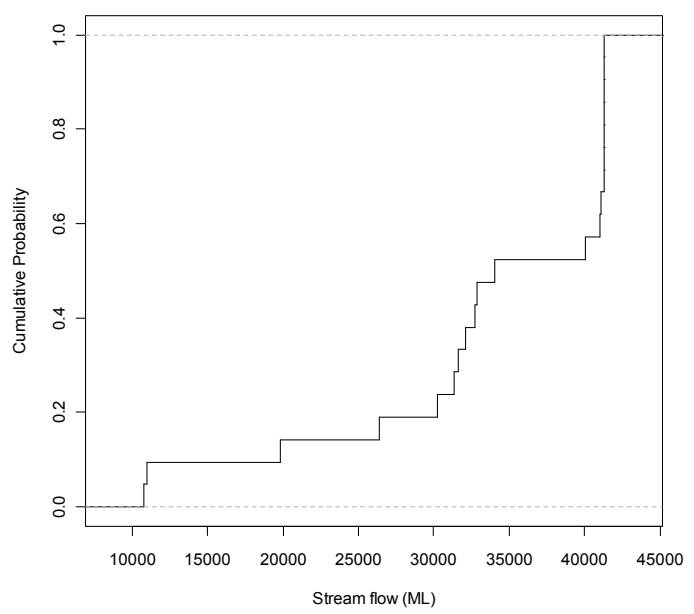

Figure 2: Empirical cumulative probability distribution of February’s stream flow

\subsection{Environmental Flow}

Environmental flow (EF) is defined as the stream flow required to maintain appropriate environmental conditions in a waterway. EFs have been altered by summer dominated irrigation in catchments. Restoring EFs would reduce the amount of water during summer and increase water during winter. 
Development of EF rules was undertaken using expert knowledge on fish and invertebrate ecology, vegetation and nutrient dynamics and geomorphology. Specific objectives (e.g. pool habitat for Murray Cod) were developed by an expert panel of ecologists into environmental flow 'rules' for each objective using hydraulic models and hydrologic data sets to quantify the rules (timing, magnitude, frequency, duration). Prioritisation of flow rules was based on a subjective independent assessment by each of the panel members ranking objectives with the median of these rankings used to identify overall rank order. The flow rules were then used as input into the hydrologic tool Eflow Predictor (eWater CRC, www.ewater.com.au) to develop environmental water demand as a time series.

In an attempt to quantify the outcomes maintaining environmental flows, two preliminary analysis are carried out.

i. Wetland locations are mapped out using digital elevation map (1m resolution and elevation accuracy of $+/-15 \mathrm{~cm}$ ) derived out of LiDAR survey by Goulburn Broken Catchment Management Authority in 2007. These data were quantified to develop the potential wetland area under high channel flow conditions.

ii Series of simulated flows from Source River were subject to demographic modelling to represent ecological dynamics in response to flow. Fundamentally populations are regulated by rates of fecundity, growth and mortality. This approach resulted in quasi-extinction probabilities for four fish species in the Broken River.

\section{RESULTS AND DISCUSSION}

Catchment wide irrigation and environmental demands and aggregate gross margin were analysed for moderate, wet and dry seasons (Table 1). Demand for irrigation and environment are high at different times.

Table 1. Irrigation and environmental demand

\begin{tabular}{lrrrr}
\hline Month & \multicolumn{2}{c}{ Irrigation demand (ML) } & \multicolumn{2}{c}{ Environmental Demand (ML) } \\
\hline & Normal & Wet & Dry & All Seasons \\
Jul & & & 4296 \\
Aug & & & 4622 \\
Sep & 569 & 454 & 770 & 4886 \\
Oct & 1763 & 1293 & 2513 & 6986 \\
Nov & 2114 & 1763 & 2774 & 2012 \\
Dec & 3679 & 3283 & 4382 & 5223 \\
Jan & 5016 & 4960 & 5653 & 1215 \\
Feb & 4236 & 4085 & 4809 & 1070 \\
Mar & 2608 & 2439 & 3294 & 1011 \\
Apr & 884 & 798 & 1276 & 623 \\
May & & & 1222 \\
Jun & & & & 3120 \\
\hline
\end{tabular}

Implications of meeting environmental demand at moderate, wet and dry scenarios on agricultural profit is tabulated below (Table 2). The opportunity cost of forgone agricultural profit is very high during dry season. Higher opportunity cost can be softened by considering the carryover of water and allowing trading of water between high and low value enterprises. Further consolidating irrigation to an area on soils more suitable for irrigation could enhance agricultural productivity and reduce the marginal costs of water supply. 
Environmental improvements in meeting the environmental demand is quantified in terms of area of wetlands and survival probability for fish population. Table 3 gives the probability that population size decreases below a certain threshold (200 adult fish in this example) at any point in time. For each flow scenario the model generates 1000 population trajectories - the proportion of them that decline to 200 or less adult fish is the probability.

Table 2. Economic implications

\begin{tabular}{|l|l|c|c|c|}
\hline Variable & Scenario & Moderate & Wet & Dry \\
\hline $\begin{array}{l}\text { Without } \\
\text { Environment }\end{array}$ & Gross Margin(\$000) & 12,538 & 14,3538 & 12,077 \\
\hline With Environment & Gross Margin(\$000) & 10,847 & 10,920 & 8,530 \\
\hline & $\begin{array}{l}\text { Opporunity cost } \\
(\$ 000)\end{array}$ & 1,690 & 1,618 & 3,548 \\
\hline
\end{tabular}

Table 3. Quasi-extinction probabilities for four fish species in the Broken River, Victoria, under two different flow scenarios.

\begin{tabular}{lcc}
\hline Species & Higher flow & Low Flow \\
\hline Murray Cod & 0.27 & 0.37 \\
Golden Perch & 0.25 & 0.13 \\
Carp Gudgeon & 0.54 & 0.63 \\
Australian Smelt & 0.01 & 0.02 \\
Sum over all species & 1.07 & 1.15 \\
Product over all species & 0.0004 & 0.0006 \\
\hline
\end{tabular}

This paper focuses on economic trade -offs from diverting water to environment from irrigated agriculture under different scenarios in the Broken river catchment of northern Victoria. Total ecosystem services need to be valued in terms of biodiversity and scenic benefits of sustained fish population and improved wetlands.

\section{ACKNOWLEDGEMENTS}

The Farms Rivers and Markets Project is an initiative of Uniwater and funded by the National Water Commission, the Victorian Water Trust, The Dookie Farms 2000 Trust (Tallis Trust) and the University of Melbourne. The project is supported by the Departments of Sustainability and Environment and Primary Industry, the Goulburn Broken Catchment Management Authority and Goulburn-Murray Water.

\section{REFERENCES}

DPI. (2009). Victorian Land Use Information System: Department of Primary Industires, Victoria.

eWater. (2011). Source Rivers. from http://www.ewater.com.au/products/ewater-source/for-rivers/

GMWater. (2011). Broken Basin. from http://www.g-mwater.com.au/waterresources/catchments/brokenbasin 
Johnson, I. R., Chapman, D. F., Snow, V. O., Eckard, R. J., Parsons, A. J., Lambert, M. G., et al. (2008). DairyMod and EcoMod: biophysical simulation models for Australia and New Zealand. .Aust.ralian Journal of Experimental Agriculture 48, 621-631.

Keating, B. A., Carberry, P. S., Hammer, G. L., Probert, M. E., \& Robertson, M. J. (2003). An overview of APSIM, a model designed for farming systems simulation. European Journal of Agronomy 18, 267288.

Kingsford, R. T. (2000). Ecological impacts of dams, water diversions and river management on floodplain wetlands in Australia. Austral Ecology 25, 109-127.

Walker, K. F., \& Thoms, M. C. (1993 ). Environmental-Effects of Flow Regulation on the Lower River Murray. Australia. Regulated Rivers-Research \& Management 8, 103-119.

Young, M. D. (2010). Managing environmental water. In J. Bennett, R. T. Kingsford, R. H. Norris \& M. D. Young (Eds.), Making decisions about environmental water allocations, Research Report. Surry Hills, NSW: Australian Farm Institute. 